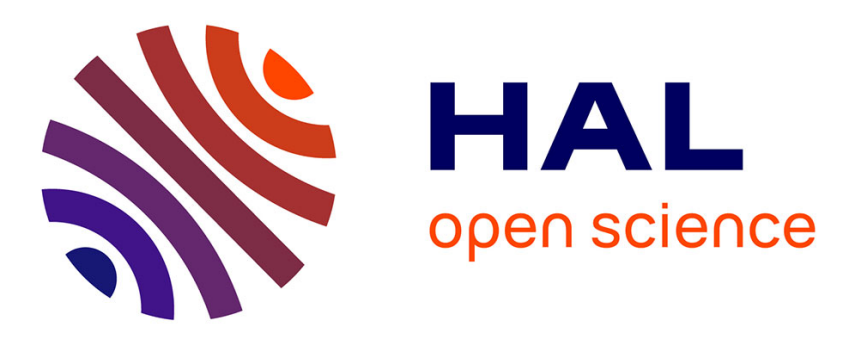

\title{
Branched-chain 2-oxoacids transamination increases "GABA-shunt" metabolism and insulin secretion in isolated islets
}

Javier Pizarro-Delgado, Inés Hernández-Fisac, Rafael Martín-Del-Río, Jorge

Tamarit-Rodriguez

\section{To cite this version:}

Javier Pizarro-Delgado, Inés Hernández-Fisac, Rafael Martín-Del-Río, Jorge Tamarit-Rodriguez. Branched-chain 2-oxoacids transamination increases "GABA-shunt" metabolism and insulin secretion in isolated islets. Biochemical Journal, 2009, 419 (2), pp.359-368. 10.1042/BJ20081731 . hal00479090

\section{HAL Id: hal-00479090 https://hal.science/hal-00479090}

Submitted on 30 Apr 2010

HAL is a multi-disciplinary open access archive for the deposit and dissemination of scientific research documents, whether they are published or not. The documents may come from teaching and research institutions in France or abroad, or from public or private research centers.
L'archive ouverte pluridisciplinaire HAL, est destinée au dépôt et à la diffusion de documents scientifiques de niveau recherche, publiés ou non, émanant des établissements d'enseignement et de recherche français ou étrangers, des laboratoires publics ou privés. 


\section{BRANCHED-CHAIN 2-OXOACIDS TRANSAMINATION INCREASES "GABA- SHUNT” METABOLISM AND INSULIN SECRETION IN ISOLATED ISLETS}

Short title: Branched-chain 2-oxoacids' transamination increase islet GABA metabolism and insulin secretion

Javier Pizarro-Delgado*, Inés Hernández-Fisac ${ }^{*}$, Rafael Martín-del-Río ${ }^{\dagger}$ and Jorge Tamarit-Rodriguez ${ }^{* *}$

*Department of Biochemistry, Medical School, Complutense University, Madrid-28040, Spain; †Research Department, Hospital “Ramón y Cajal”, Madrid-28034, Spain

Key words: Islets, insulin, GABA, branched-chain 2-oxoacids' transaminase, GABA transaminase, GABA metabolism.

${ }^{\ddagger}$ Author to whom all correspondence should be addressed:

Jorge Tamarit-Rodríguez, Departamento de Bioquímica, Facultad de Medicina, Universidad Complutense, Madrid-28040. Spain

Phone no.: +34-91-3941449; Fax no.: +34-91-3941691; E-mail : tamarit@ med.ucm.es

\footnotetext{
${ }^{1}$ Abbreviations: $\mathrm{BCAT}_{\mathrm{c}}$ and $\mathrm{BCAT}_{\mathrm{m}}$ (branched-chain amino acid transferase, cytosolic and mitochondrial isozymes, respectively); 2OGdh (2-oxoglutarate dehydrogenase); GDH (glutamic acid dehydrogenase); GAD (glutamic acid decarboxylase); GABA-T (GABA transaminase); SSA-R (semialdehyde succinic acid reductase); SSA-dh (semialdehyde succinic acid dehydrogenase); MDH (malic enzyme); BCKA (branchedchain 2-oxoacids): KIC (oxo-4-methylpentanoate or $\alpha$-ketoisocaproate), KMV (oxo-3methylpentanoate or $\alpha$-keto- $\beta$-methylpentanoate), KC (oxohexanoate or $\alpha$ ketocaproate), KIV (oxo-3-methylbutyrate or $\alpha$-ketoisovalerate); MVA (4-methylvaleric acid); 2OG (2-oxoglutarate); GABA ( $\gamma$-amino butyric acid); GHB ( $\gamma$-hydroxibutyrate).
} 


\begin{abstract}
We have previously shown that oxo-4-methylpentanoate promotes islet GABA metabolism and stimulates insulin secretion. The main aim of this work was to explore the participation of the transamination of branched-chain 2-oxoacids in these processes with the aid of several inhibitors of this enzyme activity. No correlation was found between the transamination of branched-chain 2-oxoacids in islet homogenates and insulin secretion. However, in vivo transamination rates correlated better with the secretion capacity of the different branched-chain 2-oxoacids. Gabapentin, a specific inhibitor of the cytosolic isozyme, showed greater potential to decrease the in vitro transamination rates of oxo-3-methylbutyrate and oxo-3-methylpentanoate than those of oxo-4-methylpentanoate and oxohexanoate; this correlated with its capacity to decrease insulin secretion. 4-Methylvaleric acid very strongly inhibited the transamination of all the branched-chain 2-oxoacids and blocked their capacity to decrease islet GABA and to stimulate insulin secretion. $70 \mathrm{mM} \mathrm{KCl}$ stimulated islet $\mathrm{GABA}$ release, subsequently decreasing its tissue concentration. This "non metabolic" decrease of GABA suppressed the second phase of insulin secretion triggered by oxo-4-methylpentanoate and oxohexanoate. Oxo-4-methylpentanoate and oxo-3-methylpentanoate suppressed dosedependent 2-oxoglutarate dehydrogenase activity in islet homogenates. In conclusion: 1. The transamination of branched-chain 2-oxoacids is more important to the stimulation of insulin secretion than their catabolism. 2. Transamination decreases islet GABA concentrations by promoting GABA metabolism. 3. Inhibition of 2-oxoglutarate dehydrogenase by branched-chain 2-oxoacids may increase metabolic flux in the "GABA-shunt" at the expense of reduced TCA cycle flux.
\end{abstract}




\section{INTRODUCTION}

Branched-chain 2-oxoacids (also known as branched-chain $\alpha$-keto acids, BCKA) trigger a biphasic secretion of insulin in perifused rat islets which is similar in form to that stimulated by high glucose [1-4]. Early studies showed that BCKA were transaminated in a reaction probably catalyzed by a specific branched-chain 2-oxoacid aminotransferase (BCAT) activity [5-8]. Moreover, they can be oxidised to $\mathrm{CO}_{2}$ an acetoacetate $[5,9,10]$ and it has been shown that oxo-4-methylpentanoate (also known as $\alpha$-ketoisocaproate, KIC) is oxidized at a similar rate to high glucose and its stimulation of insulin secretion might share a common mechanism with the sugar, consisting of an increased catabolic rate [11]. As BCKA may generate 2-oxoglutarate (2OG) in their transamination reaction with glutamate [8] and hence feed the tricarboxylic acid cycle, their different secretory capacities might also depend on their different rates of transamination. However, this turned out not to be the case and oxo-3-methylbutyrate (also known as $\alpha$-ketoisovalerate, KIV), which does not stimulate insulin secretion, showed the maximum rate of transamination in islet homogenates [6]. Since it was found that L-leucine activates glutamate dehydrogenase (GDH) (12), KIC transamination gained importance as a putative mechanism for increasing energy production and hence insulin release [7]. However, most of the branched chain $\alpha$-amino acids (Val, Ileu, norLeu), except L-leucine, are not GDH-activators even though some of their corresponding 2-oxocarboxylic acids may trigger a biphasic insulin secretion (oxo-3-methylpentanoate and oxohexanoate, also known as $\alpha$-keto- $\beta$-methyl valeric acid or KMV and $\alpha$-ketocaproic acid or KC, respectively) [8]. It has therefore not yet been settled which is the main metabolic process contributing to the stimulation of insulin secretion by BCKA in $\beta$-cells: their increased catabolism (oxidation), their transamination rate and the generation of $20 \mathrm{G}$, and/or the stimulation of GDH.

BCAT activity is present as two isoenzymes in the brain: a cytosolic one (BCATc) predominates in neurones whereas a mitochondrial form (BCATm) is more generally expressed in astrocytes and peripheral tissues [13]. Both enzyme activities have been demonstrated in islets of ob/ob mice and no preference for any of the two was found for the BCKA secretagogues KIC or KC [7]. The neuroactive drug gabapentin (1(aminomethyl)cyclohexaneacetic acid) is a rather specific competitive inhibitor of BCAT-c with a $\mathrm{Ki}(0.8-1.4 \mathrm{mmol} / \mathrm{l})$ value similar to the $\mathrm{Km}$ for L-leucine whereas much higher concentrations $(65,4 \mathrm{mmol} / \mathrm{l})$ are required to inhibit L-leucine binding to BCATm [14]. This drug, in combination with others, will be used to characterize the isozyme pattern of BCKA transamination in an attempt to explore its relationship with the capacity to stimulate insulin secretion.

KIC has also been found to be capable of significantly reducing intracellular GABA levels in rat islets [15]. As the rate of GABA release was not modified by KIC and no intracellular accumulation of L-leucine could be demonstrated (it accumulated extracellularly), it was proposed that the $20 \mathrm{O}$ generated in the transamination reaction might feed GABA-transaminase activity and promote metabolism of the amine in the GABA-shunt [15]. BCKA are known to inhibit the mitochondrial metabolism of $2 \mathrm{OG}$ [16] as well as 2-oxoglutarate dehydrogenase (2OGdh) activity [17]. If this could be demonstrated in islet cells, the idea that BCKA stimulate insulin secretion by increasing "GABA-shunt" metabolism would be reinforced. Therefore, the aim of this study was to investigate the dependence of BCKA capacity to stimulate insulin secretion and to decrease islet GABA on their rate of transamination using BCAT inhibitors. 


\section{Experimental}

\section{Materials}

Collagenase P was obtained from Roche Diagnostics S.L. (Barcelona, Spain). Bovine serum albumin (BSA), BCAT inhibitors, and most of the organic compounds were obtained from Sigma-Aldrich Química S.A. (Madrid, Spain). Rat insulin was from Linco Research, Inc. (St. Charles, Missouri, U.S.A.). $\mathrm{Na}^{125} \mathrm{I}$ was obtained from Amersham Iberica S.A. (Madrid, Spain). DL- $\alpha$-mehylleucine was from Acros Organics (NJ, U.S.A.). Inorganic compounds and organic solvents were obtained from VWR International Eurolab S.L.(Spain).

\section{Methods}

Islets were isolated from the pancreas of male Wistar-albino rats (250-275 g BW) by collagenase digestion. Insulin secretion was studied in perifused or incubated islets. Two groups, each of 40 rat islets, were perifused in parallel and at a flow rate of 0.5 $\mathrm{ml} / \mathrm{min}$ with Krebs-Ringer, buffered with $0.5 \mathrm{mM} \mathrm{NaHCO}_{3}$ and $20 \mathrm{mM}$ HEPES, supplemented with $0.5 \%$ FFA-free BSA $(\mathrm{KRBH})$, and heated at $37^{\circ} \mathrm{C}$. The perifusion pattern was similar in all the experiments. After a pre-perifusion period of 45 minutes under basal conditions (in the absence of nutrients or at non-stimulatory concentrations of substrates), the perifusion medium was switched to one containing the test substances and maintained for the next 30 minutes. Finally, the medium was changed back to preperifusion conditions where it was maintained for the last 25 minutes. The perifusate was collected at 1 minute intervals during the last 60-70 minutes of perifusion and its insulin concentration radioimmunologically measured. Alternatively, three batches each of ten islets were incubated in $1 \mathrm{ml}$ of $\mathrm{KRBH}$ at $37^{\circ} \mathrm{C}$ for 60 minutes and the concentration of insulin released in the incubation medium was radioimmunologically measured. Pig insulin was radio-iodinated with $\mathrm{Na}^{125} \mathrm{I}$ [18] and rat insulin was used as a standard in the radioimmunoassay of insulin. Insulin antiserum was kindly provided by Dr. Janove Sehlin from the Department of Medical Cell Biology at the University of Umeå (Sweden).

Islet $\alpha$-amino acids were separated by reverse-phase HPLC after precolumn derivatization with o-phthalaldialdehyde [19] and quantified by fluorescence detection. Islets (groups of 20) were incubated for 60 minutes at $37^{\circ} \mathrm{C}$ in $70 \mu \mathrm{l}$ of the same buffer as that used in perifusions. Incubations were stopped by placing the tubes containing the islets on ice. The medium was aspirated and the islets were washed twice with $100 \mu \mathrm{l}$ of cold PBS. Finally, $30 \mu \mathrm{l}$ of $10 \%$ (w/v) 5-sulfosalicylic acid were added in order to extract islet amino acids. Final extracts were kept at $-40^{\circ} \mathrm{C}$ until their amino acid content was determined. Twelye amino acids were regularly identified and separated in the extracts and they were measured with a sensitivity close to 1 pmol (Asp, Glu, Ser, Gln, His, Gly, Thr, Arg, Tau, Ala, Tyr, and GABA). Occasionally, the gradient elution profile of the chromatographic separation was changed in order to separate and quantify also branched-chain $\alpha$-amino acids (Leu, Ileu, Val). Islet DNA was measured with a fluorometric method [20] in an extract of islets that had been previously sonicated (four times, ten strokes at $10 \%$ of the cycle and the minimum potency of a Branson sonifier 450) in $100 \mu 15 \mathrm{mmol} / \mathrm{l} \mathrm{NaOH}$. In experiments aimed at investigating the release of amino acids, islets (groups of 30) were incubated for 60 minutes at $37^{0} \mathrm{C}$ in $70 \mu \mathrm{l}$ of the same buffer as that used in perifusions. After stopping the incubation on ice, $50 \mu 1$ of the supernatant was withdrawn and stored frozen until amino acid measurement was 
performed. The remaining medium was discarded and the islets were processed as described before for the measurement of their amino acid content.

2OGdh activity in islets' homogenates was studied as the amount of NADH produced at saturating concentrations of $2 \mathrm{OG}(5 \mathrm{mM})$ and $\mathrm{NAD}^{+}(2.5 \mathrm{mM})$ and measured fluorometrically in a multiwell plate (Costar assay plate no. 3915, Corning Incorporated, NY, U.S.A.) recorder (Varioskan model, Bioanalysis Labsystems S.A., Barcelona, Spain). Isolated islets were homogenized by sonication (four times, ten strokes at $10-20 \%$ of the cycle and the minimum potency of a Branson sonifier 450$)$ in a buffer $\left(10 \mathrm{mM} \mathrm{KH} \mathrm{PO}_{4}\right.$ and $0.5 \mathrm{mM}$ EDTA, $\left.\mathrm{pH}=7.2\right)$ containing: leupeptin $(60 \mu \mathrm{M})$, aprotinin $(0.0188 \mathrm{TIU} / \mathrm{ml})$, PMSF (2 mM in DMSO), $\beta$-mercaptoethanol $(10 \mathrm{mM})$, and Triton-X100 $(0.5 \%, \mathrm{vol} / \mathrm{vol})$. The islet homogenate was then centrifuged at $4^{\circ} \mathrm{C}$ and $141,500 \mathrm{~g}$ for 30 minutes in a 100.Ti rotor of the ultracentrifuge model Optima ${ }^{\mathrm{TM}}$-L-100 XP (Beckman Coulter España S.A.). The enzyme reaction was performed in the same buffer supplemented with $2 \mathrm{mM}$ oxamate, $4 \mu \mathrm{M}$ rotenone, $0.5 \mathrm{mM}$ coenzyme A, 0.3 $\mathrm{mM}$ thiamine pyrophosphate, $2.5 \mathrm{mM}$ dithiotreitol, $0.8 \mathrm{mM} \mathrm{CaCl}_{2}, 1 \mathrm{mM} \mathrm{MgCl}, 5$ $\mathrm{mg} / \mathrm{ml} \mathrm{BSA}$ and the substrates. The enzyme activity was calculated as the slope of the linear increase of NADH fluorescence expressed as the amount of formed product / min $\mathrm{x} \mathrm{mg}$ protein by reference to a nucleotide standard curve. The amount of protein was measured in the islet extracts with the method of Lowry [21] and BSA was used as the standard.

Branched-chain 2-oxoacid aminotransferase activity (BCAT) was measured in islets' homogenates as the amount of the branched-chain $\alpha$-amino acid (Leu, Ileu, nor-Leu or Val) produced at saturating concentrations $(1 \mathrm{mM})$ of the branched-chain $\alpha$-keto acid (KIC, KMV, KC or KIV, respectively) and L-glutamate $(2 \mathrm{mM})$. Each branched-chain $\alpha$-amino acid was isocratically separated by reverse-phase HPLC and fluorometrically detected after its derivatization with o-phtaladialdehyde, as described above for the measurements of islet $\alpha$-amino acids. The reaction was linear for at least 20 minutes and the amount of $\alpha$-amino acid accumulated during this time period was used to calculate enzyme activity. Isolated islets were homogenized by sonication (four times, ten strokes at $10 \%$ of the cycle and the minimum potency of a Branson sonifier 450) in a buffer (50 $\mathrm{mM} \mathrm{KH} \mathrm{KH}_{2} \mathrm{PO}_{4}$ and $1.0 \mathrm{mM}$ EDTA, $\left.\mathrm{pH}=7.8\right)$ containing: leupeptin $(60 \mu \mathrm{M})$, aprotinin (0.0188 TIU/mi), PMSF (2 mM in DMSO), $\beta$-mercaptoethanol (1.4 mM), and Triton-X100 $(0.5 \%, \mathrm{vol} / \mathrm{vol})$. The islet homogenate was then centrifuged at $4^{\circ} \mathrm{C}$ and $141,500 \mathrm{~g}$ for 30 minutes in a 100.Ti rotor of an ultracentrifuge (model Optima ${ }^{\mathrm{TM}}$-L-100 XP, Beckman Coulter España S.A.). The enzyme reaction was performed in the same buffer supplemented with $50 \mu \mathrm{M}$ pyridoxal phosphate and the two substrates.

All the experimental data are here presented as the mean values $\pm \mathrm{SE}$, and the numbers of separate experiments are given in parentheses. Statistical comparisons were performed with non-paired, two-tailed Student's t tests.

\section{RESULTS}

Effect of BCAT inhibitors on insulin secretion.

BCKA showed different potencies of stimulation of insulin secretion when tested on perifused islets at $10 \mathrm{mM}$ (Fig.1). KIC and KC stimulated a similar, biphasic, secretory response that was slightly higher than that triggered by KMV. KIV only induced a small first phase release and an even lower second phase. In a preliminary screening, at a fixed concentration, of the capacity of different BCAT inhibitors to modify BCKA- 
stimulation of insulin secretion, a greater sensitivity of KMV towards $10 \mathrm{mM}$ DL- $\alpha$ methylleucine $(-35.3 \pm 6.8 \%, \mathrm{n}=7 ; \mathrm{p}<0.01)$ and $5 \mathrm{mM}$ gabapentin $(-60.4 \pm 8.8 \%, \mathrm{n}=8$; $\mathrm{p}<0.0004)$ was observed, as compared with KIC, which was not affected at all. In fact, $5 \mathrm{mM}$ gabapentin suppressed within $52 \%$ the second phase of KMV-induced insulin release without modifying the first phase (Fig 2). However, $10 \mathrm{mM}$ 4-methylvaleric acid (MVA), a L-leucine structural analogue (13), was more effective than the other two inhibitors in the suppression of both KMV (-92.4 $\pm 1.6 \%, \mathrm{n}=8 ; \mathrm{p}<0.001)$ and KIC ($94.7 \pm 0.5 \%, \mathrm{n}=8 ; \mathrm{p}<0.001)$ stimulation of insulin secretion.

As shown in Table 1, KMV and KIC exhibited a different sensitivity towards gabapentin-induced inhibition of their secretory response: whereas the response triggered by $10 \mathrm{mM}$ KMV was significantly decreased by $10(-37 \%)$ and $50 \mathrm{mM}(-59$ $\%)$ gabapentin, $10 \mathrm{mM}$ KIC-stimulation was resistant to $10 \mathrm{mM}(-14 \%)$ and it was suppressed, but to a lower degree, by $50 \mathrm{mM}(-38 \%)$ gabapentin. In batch-type incubations, KIV did not increase insulin secretion above the basal level, but its response was strongly potentiated by $10 \mathrm{mM}$ L-glutamine (Table 1) and this potentiation was dose-dependently decreased by $10(-57 \%)$ and $50 \mathrm{mM}(-77 \%)$ gabapentin. MVA suppressed very efficiently, and dose-dependently, $10 \mathrm{mM}$ KICinduced secretion, up to $-90 \%$ at $20 \mathrm{mM}$ (Table 1).

Islet viability after 30 minutes' (as in the perifusions) exposure to BCAT inhibitors was checked after washing the islets and changing the medium: Pre-treatment of islets with either $10 \mathrm{mM}$ KIC alone or together with $50 \mathrm{mM}$ gabapentin or $20 \mathrm{mM}$ VMA did not modify their subsequent insulin secretory response to $20 \mathrm{mM}$ glucose, nor their insulin content (results not shown).

BCKA transamination

BCKA transamination with L-glutamate was measured in islet homogenates measuring the linear accumulation of the resulting $\alpha$-amino acid and the effect of a concentration range of different inhibitors investigated. A hierarchy of transamination activities was observed among the different BCKA assayed: the highest was obtained with KIV, followed in a decreasing order by KIC, KMV and KC (Table 2). KIV and KMV transaminations were more sensitive to the inhibitory effect of gabapentin than those of $\mathrm{KIC}$ and KC: whereas transamination of the two former were significantly decreased by 2 and $10 \mathrm{mM}$ gabapentin, the inhibitor did not modify the transamination of the latter two. Moreover, $50 \mathrm{mM}$ gabapentin caused a greater suppression of transamination with $\operatorname{KIV}(-85.5 \%)$ and $\mathrm{KMV}(-78.3 \%)$ than with either KIC (-61.0 \%) and KC (-55.6\%). MVA behaved as a potent inhibitor of BCKA transamination (over $87 \%$ at $20 \mathrm{mM}$ ) and did not show any preference for a particular branched-chain $\alpha$-keto acid (Table 2). DL$\alpha$-methylleucine suppressed $10 \mathrm{mM}$ KIC-transamination at 10 and $20 \mathrm{mM}$ within 33.0 and $43.5 \%$, respectively (Table 2 ).

BCKA transamination activity was also measured in intact islets preloaded for 1 hour with various L-glutamine concentrations $(0,0.5$ and $10.0 \mathrm{mM})$ : the amount of $\alpha$-amino acids, either released or remaining in the islets, was measured after washing the islets (to rid them of Gln) and incubating them for a second hour in the presence of a $10 \mathrm{mM}$ concentration of the different BCKAs. No significant accumulation of any of the branched chain $\alpha$-amino acids (Leu, Ileu or Val) could be detected in the islets at any Lglutamine concentration (results not shown). As shown in Table 3, the amount of the branched-chain $\alpha$-amino acid released (in vivo transamination) increased with the concentration of L-glutamine to which islets were pre-exposed during the first hour. In 
the absence of L-glutamine, the production of Leu was significantly greater than that of Ileu but this difference disappeared at either 0.5 or $10.0 \mathrm{mM}$ L-glutamine. By contrast, the amount of Val released was consistently lower than that of Leu at all the Lglutamine concentrations tested (Table 3). Both, KMV and KIV, significantly increased the islet content of Asp and Glu with respect to the control and also in comparison to KIC (Table 3). KIC was the only BCKA that significantly decreased islet GABA content in the absence of L-glutamine (Table 3). However, at a L-glutamine concentration close to the physiological plasma concentration $(0.5 \mathrm{mM})$ or higher $(10$ $\mathrm{mM}$ ), all three BCKA significantly diminished the islet GABA content.

In order to check the hypothesis that BCKA transamination is responsible for increased GABA metabolism and therefore for the stimulation of insulin secretion, we investigated whether the inhibition of transamination would also block the reduction of islet GABA. For that purpose, MVA was used as the BCAT inhibitor because it suppressed with similar efficiency KIC-induced insulin secretion and the rate of $\alpha$-keto acid transamination to Leu in islet homogenates. The effect of MVA, measured with the same experimental design used to evaluate in vivo transamination (see preceding paragraph), was tested on islets that had been pre-loaded for 1 hour with $10 \mathrm{mM} \mathrm{L}$ glutamine. $10 \mathrm{mM}$ MVA suppressed within $67 \%$ the release of Leu $(4.0 \pm 0.4, \mathrm{n}=8 \mathrm{vs}$. $1.3 \pm 0.2 \mathrm{pmoles} / \mathrm{ng}$ DNA, $\mathrm{n}=8 ; \mathrm{p}<0.0001)$ evidencing its efficient inhibition of KIC transamination in intact islets. In contrast, it did not modify the release of any other $\alpha-$ amino acid (results not shown). Simultaneously, MVA increased by $57 \%$ the islet GABA content in the presence of $10 \mathrm{mM} \mathrm{KIC} \mathrm{(} 3.7 \pm 0.5, \mathrm{n}=8$ vs. $2.4 \pm 0.2$ pmoles/ng DNA, $n=8 ; p<0.028)$ and induced a parallel decrease of Asp $(1.3 \pm 0.2, n=8$ vs. $2.3 \pm$ 0.2 pmoles/ng DNA, $n=8 ; \mathrm{p}<0.001)$ and Glu $(0.7 \pm 0.06, \mathrm{n}=8$ vs. $1.3 \pm 0.2$ pmoles $/ \mathrm{ng}$ DNA; $\mathrm{p}<0.008)$. The islet content of Leu was not modified at all $(0.19 \pm 0.02, \mathrm{n}=8 \mathrm{vs}$. $0.18 \pm 0.04$ pmoles/ng DNA, $n=8$; N.S.). The membrane permeable GABA analogue ethyl-GABA (eGABA) increased the islet content of GABA in the presence of $10 \mathrm{mM}$ KIC by $66 \%$ at $1.5 \mathrm{mM}(3.9 \pm 0.4, n=8$ vs. $2.4 \pm 0.2$ pmoles/ng DNA, $n=8 ; p<0.002)$ and elevated it three-fold at $5 \mathrm{mM}(7.0 \pm 0.7, \mathrm{n}=8$ vs. $2.4 \pm 0.2$ pmoles/ng; $\mathrm{p}<0.002)$. Neither 1.5 nor $5.0 \mathrm{mM}$ eGABA modified the rate of KIC transamination measured as Leu release $(4.2 \pm 0.4, \mathrm{n}=8$ and $4.0 \pm 0.3, \mathrm{n}=8$ vs. $4.0 \pm 0.6$ pmoles/ng DNA, $\mathrm{n}=8)$.

Effect of the intracellular GABA concentration on insulin secretion.

The islet GABA content is dose-dependently increased by the extracellular L-glutamine concentration and reaches close to the maximum level at the physiological plasma concentration of the $\alpha$-amino acid $(0.5$ to $1.0 \mathrm{mM})$ [22]. We have shown before [15], and corroborated in this work (Table 3), that KIC efficiently reduces the islet content of GABA at any L-glutamine concentration. This effect was ascribed to $2 \mathrm{OG}$ generation in the transamination of KIC to Leu and the subsequent GABA transamination with the generated 2OG.

We showed above that increasing the intracellular GABA concentration at two different levels with eGABA (1.5 and $5.0 \mathrm{mM}$ ) did not modify the rate of KIC transamination measured as the release of Leu. This apparently suggests that the observed suppression of intracellular GABA does not limit the rate of KIC transamination but perhaps restricts GABA transamination. We therefore explored whether the secretory response to KIC might be improved by increasing intracellular GABA levels with the membrane permeable analogue. As shown in Fig 3A, the simultaneous perifusion of rat islets with $10 \mathrm{mM}$ KIC together with $1 \mathrm{mM}$ eGABA did not modify the first phase of insulin secretion but strongly decreased the sustained, second phase of insulin release by more than $50 \%(16.2 \pm 3.0, \mathrm{n}=4$, vs. $33.5 \pm 3.0 \mathrm{ng}$ insulin/ $20 \mathrm{~min} \times 40$ islets, $\mathrm{n}=6, \mathrm{p}<0.005)$. 
A further increase of intracellular GABA with $5 \mathrm{mM}$ eGABA decreased slightly more ($77 \%)$ the second phase of KIC-induced insulin secretion $(5.4 \pm 1.4, \mathrm{n}=5$, vs. $23.3 \pm 4.4$ ng insulin/ 20min x 40 islets, $\mathrm{n}=4 ; \mathrm{p}<0.002$ ) but did not modify first phase release (results not shown). The second phase of the secretory response to $10 \mathrm{mM} \mathrm{KMV}$ was similarly decreased by $5 \mathrm{mM}$ eGABA within $86 \%(4.5 \pm 1.7$, $\mathrm{n}=6$, vs. $32.0 \pm 5.3 \mathrm{ng}$ insulin/ 20min x 40 islets, $n=4 ; \mathrm{p}<0.0004$ ) (Fig. 3B). These results suggest that islet GABA, besides being a potential metabolic substrate, might have other effects on the mechanism of insulin secretion above certain concentrations.

Preliminary results have shown that $5 \mathrm{mM}$ eGABA significantly decreases glucoseinduced insulin secretion and this effect correlated with a hyperpolarization of the $\beta$-cell plasma membrane [23]. Therefore, we tried to counteract eGABA-induced decrease of the secretory response to KIC by depolarizing the islets with $70 \mathrm{mM} \mathrm{KCl}$ : surprisingly, depolarization itself suppressed the second phase of release within $61 \%(8.8 \pm 0.8, \mathrm{n}=$ 27 vs. $22.6 \pm 1.7 \mathrm{ng}$ insulin/ $20 \mathrm{~min} \mathrm{x} 40$ islets, $\mathrm{n}=27 ; \mathrm{p}<0.0001$ ) (Fig. 4 ) whereas it had no effect on glucose $(20 \mathrm{mM})$ stimulation (results not shown). The addition of 1,5 or 10 $\mathrm{mM}$ eGABA did not modify depolarization induced suppression of the second phase of release triggered by $10 \mathrm{mM}$ KIC (results not shown). A smaller reduction of the $\mathrm{K}^{+}$electrochemical potential with $30 \mathrm{mM} \mathrm{KCl}$ did not modify the secretory response (results not shown). Whereas $70 \mathrm{mM} \mathrm{KCl}$ depolarization did not significantly affect KMV-induced release $(12.3 \pm 1.9, \mathrm{n}=4$, vs. $20.8 \pm 3.8 \mathrm{ng}$ insulin/ $20 \mathrm{~min} \times 40$ islets, $\mathrm{n}=4$; N.S.) (Fig.5A), it suppressed by $63 \%$ the second phase of secretion triggered by $10 \mathrm{mM} \mathrm{KC}(9.9 \pm 1.3, \mathrm{n}=6$, vs. $27.2 \pm 0.8 \mathrm{ng}$ insulin/ $20 \mathrm{~min} \times 40$ islets, $\mathrm{n}=5 ; \mathrm{p}<0.0001)$ (Fig 5B).

As we have hypothesized [15] that KIC stimulation of insulin secretion is at least partially dependent on the promotion of GABA metabolism, we checked whether the decrease of the $\mathrm{K}^{+}$-electrochemical potential by $70 \mathrm{mM} \mathrm{KCl}$ might interfere with the availability of GABA in the islets. For that purpose, islets were pre-loaded with $10 \mathrm{mM}$ L-glutamine for 1 hour and, after washing the remaining extracellular Gln, both islet content and the release of $\alpha$-amino acids were measured after a second hour of incubation in the presence of $70 \mathrm{mM} \mathrm{KCl}$. Table 4 shows that under this depolarizing condition, the release of GABA and taurine were increased by more than $100 \%$ and this increment was not affected by the simultaneous presence of $10 \mathrm{mM} \mathrm{KIC}$. There were corresponding decreases of both GABA and Tau contents $(-32 \%$ and $-40 \%$, respectively). It was shown again that $10 \mathrm{mM}$ KIC alone decreased within $42 \%$ islet GABA content without modifying Tau content. KIC was even capable of suppressing further GABA ( $p 0.008$ ), but not taurine, content in the presence of $70 \mathrm{mM} \mathrm{KCl}$.

Modification of 2-oxoglutarate dehydrogenase (2OGdh) activity by BCKA in islet homogenates.

This enzymatic activity competes for its substrate with GABA transaminase, the enzyme that initiates metabolism in the "GABA-shunt". The confirmation in islet homogenates that 2OGdh activity is inhibited by BCKAs, as has been demonstrated in other tissues [16, 17], would strengthen the importance of an increased "GABA-shunt" metabolism in the stimulation of insulin secretion by KIC. As shown in Table 5, KIC decreased 2OGdh activity in islet homogenates in a dose-responsive manner between 1 and $10 \mathrm{mmol} / \mathrm{l}$. At $10 \mathrm{mM}$, KIC decreased the enzyme activity to around $6 \%$ of the control. Similar effects were found in homogenates of rat cerebellum (not shown). 5 $\mathrm{mM} \mathrm{KMV}$ induced a stronger reduction of 2OGdh activity than $5 \mathrm{mM} \mathrm{KIC}$ in both islets 
and cerebellum: it almost abolished the enzymatic activity in islet homogenates (results not shown).

\section{DISCUSSION}

It has been shown recently that the secretory response to KIC in incubated mouse islets was inhibited by DL- $\alpha$-methylleucine in a concentration dependent manner although the drug effect on islet transamination was not checked [24]. We have demonstrated in this paper that DL- $\alpha$-methylleucine inhibited KIC transamination in rat islet homogenates in a concentration sensitive manner but that it did not suppress KIC-induced stimulation of insulin secretion. This different sensitivity to DL-methylleucine between mouse [24] and rat islets might be attributed to the species differences. Gabapentin is a well characterized and specific inhibitor of the cytosolic form of BCAT which is known to predominate in neurones [13]. Therefore, it was used in this study as a tool to uncover specific differences in the affinity among the different BCKA for the transaminase isoforms. Our results confirm previous evidence indicating that both cytosolic and mitochondrial BCAT activities are present in rat islets [7]. The study of the effect of a range of gabapentin concentrations on BCKA transamination in islet homogenates allows us to conclude that both $\mathrm{KIC}$ and $\mathrm{KC}$, at variance with $\mathrm{KMV}$ and $\mathrm{KIV}$, have a higher affinity for the mitochondrial than the cytosolic isoform. The existence of a mitochondrial activity might facilitate the concatenation of 2-oxoacid transaminase and GABA transaminase activities when islets are exposed to KIC and $\mathrm{KC}$ (see diagram in Figure 6). This would result in a greater efficiency of $\mathrm{KIC}$ and $\mathrm{KC}$ to reduce intracellular GABA compared to KMV and KIV which are preferentially transaminated by the cytosolic isoenzyme. This was confirmed for KIC in the present study. In previous experiments in our laboratory, it was found that $\mathrm{KC}$ induced a greater decrease of islet GABA (-53\%) than KMV (-32\%) in the absence of Gln (results not shown).

The weak capacity of KIV to decrease intracellular GABA correlates with its low secretory competence and is in apparent contradiction with its high rate of transamination in islets' homogenates. The rank of transamination activities found in this work (KIV>KIC>KMV>KC) confirms previously published results [6] in rat islets and emphasizes the lack of correlation between transamination rate and secretory strength. However, when tested in vivo, KIV conversion to Val was much lower than synthesis and release of Leu from KIC under all Gln concentrations studied; KMV transamination to Ileu was also lower than Leu formation from KIC. These differences in transamination rates may be, at least partially, determined by differences in transport rates through the plasma membrane of $\beta$-cells. They correlate better than in vitro transamination rates with the secretory potency of the different BCKA and their capacity to decrease islet GABA. In conclusion, the importance of BCKA transamination in their mechanism of stimulation of insulin secretion now seems to be settled. As a corollary, BCKA oxidation does not seem to contribute much to the stimulation of secretion, as pointed out by Rabaglia et al [24]. Moreover, it has been shown that KIC by itself is not a good substrate in isolated mitochondria but it increases ATP production in combination with L-glutamate (25). This supports our finding that KIC is mainly transaminated by the mitochondrial form of BCAT in islet cells.

If BCKA oxidation is not important, what would then be the source of metabolic energy used to initiate and maintain insulin secretion? A "non metabolic" decrease of islet GABA induced by its increased release after high $\mathrm{K}^{+}(70 \mathrm{mM} \mathrm{KCl})$ depolarization (Table 4) significantly suppressed the second phase of insulin secretion stimulated by 
KIC and KC without affecting the first one. It is plausible that the increased GABA release might restrict the availability of the amine to feed the "GABA-shunt" and this would in turn diminish the rate of ATP generation necessary to maintain sustained secretion. In support of this interpretation, it has recently been shown that islets of SUR1 knock-out mice which are permanently depolarized exhibit a diminished metabolic flow in the "GABA-shunt" [26]. Therefore, it seems that GABA is the main metabolic fuel used during the stimulation of insulin secretion by BCKA. Another argument in support of this idea is that BCKA (KIC) block 2OGdh in the Krebs cycle favouring metabolism in the "GABA-shunt" (see diagram in Figure 6). In contrast, first phase release in response to KIC might be more dependent on a direct effect of the 2oxoacids on $\mathrm{K}_{\text {ATP }}^{+}$channels at the sulfonylurea binding site that would close the channels irrespective of the ATP concentration [27,28].

At variance with KIC and KC, KMV-induced secretion was not significantly modified by $\mathrm{K}^{+}$-depolarization. The latter, as well as $\mathrm{KIV}$, are predominantly transaminated by the cytosolic isoform of BCAT and the formed 2OG might be less efficiently transported into mitochondria to serve as a susbstrate of GABA-T (see diagram in Fig. 6). Both, KMV and KIV, may be substantially metabolized to succinic acid as reflected by the increased synthesis of Asp which probably arises from transamination of oxaloacetate. The stimulation of insulin secretion by KMV is perhaps more dependent on its partial catabolism in the citric acid cycle than either $\mathrm{KIC}$ or $\mathrm{KC}$.

eGABA did not improve KIC transamination or, as expected, KIC-induced insulin secretion. Neither did it rescue the stimulation of insulin secretion by KIC after depleting islet GABA content with $70 \mathrm{mM} \mathrm{KCl}$. These data cast some doubt on the suitability of eGABA as a true analogue of GABA, a matter that is presently under investigation.

To sum up, BCKA stimulation of insulin secretion depends on their transamination rates with Glu that generates 2OG. As 2OGdh is inhibited by BCKA (KIC), 2OG is used preferentially by GABA transaminase resulting in an increased metabolic flux in the "GABA-shunt" and a decreased intracellular GABA level (Figure 6). The increased GABA metabolism would contribute to the maintenance of high ATP generation, as required for sustained insulin secretion.

\section{ACKNOWLEDGMENTS}

This work was partially supported by grant PI-06/1744, from Instituto de Salud Carlos III, Madrid (Spain). Inés Hernández-Fisac was a pre-doctoral fellow supported during four years by the Ministerio de Educación y Ciencia, Spain. Javier Pizarro Delgado is a pre-doctoral fellow partially supported by private funding (Astellas Pharma S.A., Madrid, Spain). 


\section{REFERENCES}

1. Panten U., Kriegstein E., Poser W., Scónborn J., and Hasselblatt A. (1972) Effects of L-leucine and $\alpha$-ketoisocaproic acid upon insulin secretion and metabolism of isolated pancreatic islets. FEBS Lett. 20, 225-228

2. Panten U. (1975) Effects of alpha-ketomonocarboxylic acids upon insulin secretion and metabolism of isolated pancreatic islets. Naunyn-Schmiedebergs's Arch.Pharmacol. 291, 405-420

3. Lenzen S. (1978) Effects of $\alpha$-ketocarboxylic acids and 4-pentenoic acid on insulin secretion from the perfused rat pancreas. Biochem. Pharmacol. 27, 13211324

4. Lenzen S., and Panten U. (1980) 2-oxocarboxylic acids and function of pancreatic islets in obese-hyperglycaemic mice. Biochem. J. 186, 135-144

5. Hutton J. C., Sener A., and Malaisse W. (1979) The metabolism of 4-methyl-2oxopentanoate in rat pancreatic islets. Biochem. J. 184, 291-301

6. Malaisse W., Sener A., Malaisse-Lagae F., Hutton J.C., and Christophe J. (1981) The stimulus-secretion coupling of amino acid-induced insulin release. Metabolic interaction of L-glutamine and 2-ketoisocaproate in pancreatic islets. Biochim. Biophys. Acta 677, 39-49

7. Lenzen S., Schmidt W., and Panten U. (1985) Transamination of neutral amino acids in pancreatic B-cell mitochondria. J. Biol. Chem. 260, 12629-12634

8. Lenzen S., Schmidt W., Rustenbeck I., and Panten U. (1986) 2-Ketoglutarate generation in pancreatic B-cell mitochondria regulates insulin secretory action of amino acids and 2-keto acids. Biosci. Reports 6,163-169

9. Panten U., Biermann J., and Graen W. (1981) Recognition of insulin-releasing fuels by pancreatic B-cells. $\alpha$-Ketoisocaproic acid is an appropriate model compound to study the role of $\beta$-cell metabolism. Mol. Pharmacol. 20, 76-82

10. Lenzen S., Formanek H., and Panten U. (1982) Signal function of metabolism of neutral amino acids and 2-keto acids for initiation of insulin secretion. J. Biol. Chem. 257, 6631-6633

11. Hutton J.C., Sener A., Herchuelz A., Atwater I., Kawazu S., Boschero A.C., Somers G., Devis G., and Malaisse W. (1980) Similarities in the stimulussecretion coupling mechanisms of stimulation of glucose- and 2-keto acidinduced insulin release. Endocrinology 106, 203-219

12. Sener A., and Malaisse W. (1980) L-leucine and a nonmetabolized analogue activate pancreatic islet glutamate dehydrogenase. Nature 288, 187-189

13. Goto M., Miyahara I., Hirotsu K., Conway M., Yennawar N., Islam M.M., and Hutson S.M. (2005) Structural determinants for branched-chain aminotransferase isozyme-specific inhibition by the anticonvulsant drug gabapentin. J. Biol. Chem. 280,37246-37256

14. Goldlust A., Su T.-Z., Welty D.F., Taylor C.P., and Oxender D.L. (1995) Effects of anticonvulsant drug gabapentin on the enzymes in metabolic pathways of glutamate and GABA. Epilepsy Res. 22,1-11

15. Hernández-Fisac I., Fernández-Pascual S., Ortsäter H., Pizarro-Delgado J., Martín-del-Río R., and Tamarit-Rodriguez J. (2006) Oxo-4-methylpentanoic acid directs the metabolism of GABA into the Krebs Cycle in rat pancreatic islets. Biochem. J. 400, 81-89

16. Shestopalov A.I. and Kristal B.S. (2007) Branched-chain keto-acids exert biphasic effects on $\alpha$-ketoglutarate-stimulated respiration in intact rat liver mitochondria. Neurochem. Res. 32, 947-951 
17. Patel M.S. (1974) Inhibition by the branched-chain 2-oxo acids of the 2oxoglutarate dehydrogenase complex in developing rat and human brain. Biochem. J. 144, 91-97

18. Hunter W.M., Greenwood F.C. (1962) Preparation of iodine-131 labeled human growth hormone of high specific activity. Nature 194, 495-496

19. Jones B.N., Paabo S., Stein S. (1981) Amino acid analysis and enzymatic sequence determination of peptides by an improved o-phtalaldialdehyde precolumn labeling procedure. J. Liquid Chromatogr. 4, 565-586

20. Vytasek R. (1982) A sensitive assay for the determination of DNA. Anal. Biochem. 120, 243-248

21. Lowry O. H., Rosenbrough N. J., Farr A. L. and Randall R. J. (1951) Protein measurement with the Folin phenol reagent. J. Biol. Chem. 193, 265-275

22. Fernández-Pascual S., Mukala-Nsengu-Tshibangu A., Martín-del-Río R., and Tamarit-Rodriguez J. (2004) Conversión into GABA ( $\gamma$-aminobutyric acid) may reduce the capacity of L-glutamine as an insulin secretagogue. Biochem. J. 379, 721-729

23. Tamarit-Rodriguez J., Braun M., M. Fernández-Pascual M., Pizarro-Delgado J., Hernández-Fisac I., Rorsman P. and Martín-del-Río R. (2006) Intracellular GABA accumulation suppresses glucose-induced insulin secretion in rat pancreatic islets as well as membrane depolarization in $\beta$ cells. Diabetologia 49 (Suppl.1), 299

24. Rabaglia M.E., Gray-Keller M.P., Frey B.L., Shortreed M.L., Smith L.M. and Attie A.D. (2004) $\alpha$-Ketoisocaproate-induced hypersecretion of insulin by islets from diabetes-susceptible mice. Am. J. Physiol. Endocrinol. Metab. 289, E218E224

25. Lembert N., and Idahl L.-Á. (1998) $\alpha$-Ketoisocaproate is not a true substrate for ATP production by pancreatic $\beta$-cell mitochondria. Diabetes 47: 339-344

26. Changhong L., Nissim I., Chen P., Buettger C., Najafi H., Daikhin Y., Nissim I., Collins H.W., Yudkoff M., Stanley C.A. and Matschinsky F.M. (2008) Elimination of $\mathrm{K}_{\mathrm{ATP}}$ channels in mouse islets results in elevated $\left[\mathrm{U}_{-}{ }^{13} \mathrm{C}\right] \mathrm{glucose}$ metabolism, glutaminolysis, and pyruvate cycling but a decreased $\gamma$ aminobutyric acid shunt. J. Biol. Chem. 283: 17238-17249

27. Bränström R., Efendic S., Berggren P.-O. and Larsson O. (1998) Direct inhibition of the pancreatic $\beta$-cell ATP-regulated potassium channel by $\alpha-$ ketoisocaproate. J. Biol. Chem. 273: 14113-14118

28. Heissig H., Urban K.A., Hastedt K., Zünkler B.J. and Panten U. (2005) Mechanism of the insulin-releasing action of $\alpha$-ketoisocaproate and related $\alpha-$ keto acid anions. Mol. Pharmacol. 68, 1097-1105 


\section{LEGENDS TO FIGURES}

Figure 1. Stimulation of insulin secretion in rat perifused islets by branched-chain 2oxocarboxylic acids.

Groups of 40 islets each, pre-perifused without substrates for $45 \mathrm{~min}$, were stimulated for $30 \mathrm{~min}$ (between vertical broken lines) with $10 \mathrm{mM}$ of one out of four different branched-chain 2-oxocarboxylic acids (KIC, KMV, KIV and KC represent oxo-4methyloxopentanoate, oxo-3-methylpentanoate, oxo-3-methylbutyrate and oxohexanoate, respectively). Pre-perifusion conditions were then re-established during the last $25 \mathrm{~min}$. Each perifusion was repeated a variable number of times $(\bullet, n=27$ for KIC; $\boldsymbol{\Delta}, \mathrm{n}=27$ for KMV; $\square, \mathrm{n}=6$ for KC; $\triangle, \mathrm{n}=6$ for KIV). Symbols represent means \pm S.E.M.

Figure 2. Effect of gabapentin, a specific inhibitor of the cytosolic form of the branched-chain 2-oxoacid transaminase, on insulin secretion of perifused islets stimulated by oxo-3-methylpentanoate (KMV).

Groups of 40 islets each, pre-perifused without substrates for $45 \mathrm{~min}$, were stimulated for $30 \mathrm{~min}$ (between vertical broken lines) with $10 \mathrm{mM} \mathrm{KMV}$ alone $(\boldsymbol{\Delta}, \mathrm{n}=27)$ or together with $5 \mathrm{mM}$ gabapentin $(\triangle, \mathrm{n}=6)$. Pre-perifusion conditions were then reestablished during the last $25 \mathrm{~min}$. Symbols represent means \pm S.E.M.

Figure 3. Effect of ethyl-GABA (eGABA) on insulin secretion of perifused rat islets stimulated by either oxo-4-methylpentanoate (KIC) or oxo-3-methylpentanoate (KMV).

In Figure 3A, groups of 40 islets each, pre-perifused without substrates for $45 \mathrm{~min}$, were stimulated for $30 \mathrm{~min}$ (between vertical broken lines) with $10 \mathrm{mM} \mathrm{KIC}$ alone $(\bullet, \mathrm{n}=9)$ or together with $1 \mathrm{mM}$ eGABA $(0, n=9)$. In Figure 3B, islets were stimulated with 10 $\mathrm{mM} \mathrm{KMV}$ alone $(\boldsymbol{\Delta}, \mathrm{n}=7)$ or together with $5 \mathrm{mM}$ eGABA $(\triangle, \mathrm{n}=7)$. Pre-perifusion conditions were then re-established during the last $25 \mathrm{~min}$. Symbols represent means \pm S.E.M.

Figure 4. Effect of $70 \mathrm{mM} \mathrm{KCl}$ depolarization on insulin secretion of perifused rat islets stimulated by oxo-4-methylpentanoate (KIC).

Groups of 40 islets each, pre-perifused without substrates for $45 \mathrm{~min}$, were stimulated for $30 \mathrm{~min}$ (between vertical broken lines) with $10 \mathrm{mM} \mathrm{KIC} \mathrm{alone}(\bullet, \mathrm{n}=27)$ or together with $70 \mathrm{mM} \mathrm{KCl}(\mathrm{o}, \mathrm{n}=27)$. Pre-perifusion conditions were then re-established during the last $25 \mathrm{~min}$. Symbols represent means \pm S.E.M.

Figure 5. Effects of $70 \mathrm{mM} \mathrm{KCl}$ depolarization on insulin secretion of perifused rat islets stimulated by either oxo-3-methylpentanoate (KMV) or oxohexanoate (KC).

In Figure 5A, groups of 40 islets each, pre-perifused without substrates for $45 \mathrm{~min}$, were stimulated for $30 \mathrm{~min}$ (between vertical broken lines) with $10 \mathrm{mM} \mathrm{KMV}$ alone $(\boldsymbol{\Lambda}, \mathrm{n}=$ 6) or together with $70 \mathrm{mM} \mathrm{KCl}(\triangle, \mathrm{n}=7)$. In Figure 3B, islets were stimulated with 10 
$\mathrm{mM} \mathrm{KC}$ alone $(\mathbf{\square}, \mathrm{n}=6)$ or together with $70 \mathrm{mM} \mathrm{KCl}(\square, \mathrm{n}=6)$. Pre-perifusion conditions were then re-established during the last $25 \mathrm{~min}$. Symbols represent means \pm S.E.M.

Figure 6. Scheme of the metabolic interconnections between the citric acid cycle and the "GABA-shunt".

Abbreviations used: $\mathrm{BCAT}_{\mathrm{c}}$ and $\mathrm{BCAT}_{\mathrm{m}}$ (branched-chain amino acid transferase, cytosolic and mitochondrial isozymes, respectively); 2OGdh (2-oxoglutarate dehydrogenase); GDH (glutamic acid dehydrogenase); GAD (glutamic acid decarboxylase); GABA-T (GABA transaminase); SSA-R (semialdehyde succinic acid reductase); SSA-dh (semialdehyde succinic acid dehydrogenase); MDH (malic enzyme); KIC (oxo-4-methylpentanoate or $\alpha$-ketoisocaproate), KMV (oxo-3methylpentanoate or $\alpha$-keto- $\beta$-methylpentanoate), KC (oxohexanoate or $\alpha$ ketocaproate), KIV (oxo-3-methylbutyrate or $\alpha$-ketoisovalerate); $\operatorname{GHB} \quad(\gamma$ hydroxibutyrate) 


\section{TABLES}

Table 1. Effect of two inhibitors of branched-chain 2-oxoacids' transamination activity (gabapentin and 4-methylvaleric acid) on islet insulin secretion stimulated by several 2-oxo acids.

Three groups, each of ten islets, were incubated at $37{ }^{0} \mathrm{C}$ for 1 hour in $1 \mathrm{ml}$ of Krebs-Ringer bicarbonate buffered with $0.5 \mathrm{mM} \mathrm{NaHCO} 3$ and $25 \mathrm{mM}$ Hepes $(\mathrm{pH}=7.4)$ and supplemented with FFA-free BSA. The insulin accumulated in the incubation medium was radioimmunologically measured. (KIC, KMV and KIV are oxo-4-methyloxopentanoate, oxo3-methylpentanoate and oxo-3-methylbutyrate, respectively; Gln means L-glutamine; n represents the number of experiments).

\begin{tabular}{|c|c|c|c|c|c|c|c|c|}
\hline \multicolumn{9}{|c|}{ IRI (pmol insulin / min x islet) } \\
\hline Gabapentin & $10 \mathrm{mM} \mathrm{KIC}$ & $\mathrm{n}$ & $p$ & $10 \mathrm{mM} \mathrm{KMV}$ & $\mathrm{n}$ & $10 \mathrm{mM} \mathrm{KIV} \mathrm{+10} \mathrm{mM} \mathrm{GIn}$ & $\mathrm{n}$ & $p$ \\
\hline - & $24,30 \pm 3,57$ & 4 & - & $21,84 \pm 2,80$ & 3 & $26,75 \pm 2,56$ & 4 & - \\
\hline $10 \mathrm{mM}$ & $20,89 \pm 0,45$ & 4 & N.S & $13,84 \pm 1,28$ & $4<0.0$ & $11,57 \pm 1,73$ & 5 & $<0.001$ \\
\hline $50 \mathrm{mM}$ & $14,97 \pm 1,51$ & 5 & $<0.04$ & $8,95 \pm 0,87$ & $5<0$ & $6,13 \pm 2,16$ & 3 & $<0.002$ \\
\hline 4-methylvaleric acid & $10 \mathrm{mM} \mathrm{KIC}$ & $\mathrm{n}$ & $p$ & & & & & \\
\hline- & $18,64 \pm 1,99$ & 6 & - & & & & & \\
\hline $0.5 \mathrm{mM}$ & $13,99 \pm 1,68$ & 6 & N.S & & & & & \\
\hline $2 m M$ & $10,35 \pm 1,62$ & 3 & $<0.008$ & & & & & \\
\hline $10 \mathrm{mM}$ & $4,87 \pm 1,78$ & 4 & $<0.001$ & & & & & \\
\hline $20 \mathrm{mM}$ & $1,56 \pm 0,60$ & 5 & $<0.00004$ & & & & & \\
\hline
\end{tabular}


Table 2. Effect of three enzyme inhibitors (gabapentin, 4-methylvaleric acid and DL-methylleucine) on branched-chain 2-oxoacids' transamination activity of islet homogenates (in vitro transamination rates).

Isolated islets were sonicated in a lysis buffer defined in the experimental section. The enzymatic reaction was measured as the amount of branched-chain $\alpha$-amino acid (Leu, Ileu, Val, nor-Leu) linearly accumulated at saturating concentrations of the corresponding 2-oxoacid (KIC, KMV, KIV and KC representing oxo-4-methyloxopentanoate, oxo-3-methylpentanoate, oxo-3-methylbutyrate and oxohexanoate, respectively) and L-glutamate ( 1 and $2 \mathrm{mM}$, respectively). The $\alpha$-amino acids were quantified by their fluorescence after being derivatized with o-phftaldialdehyde and separated by reverse phase HPLC. ("n" represents the number of experiments).

\begin{tabular}{|c|c|c|c|c|c|c|c|c|c|c|c|c|}
\hline \multicolumn{13}{|c|}{ transamination rate (pmol / islet x 20min) } \\
\hline Gabapentin & KIC & $\mathrm{n}$ & $p$ & KMV & $\mathrm{n}$ & $p$ & KIV & $\mathrm{n}$ & $p$ & KC & $\mathrm{n}$ & $p$ \\
\hline- & $24,27 \pm 1,30$ & 3 & - & $12,66 \pm 0,97$ & 7 & & $26,20 \pm 2,39$ & 6 & - & $10,27 \pm 0,15$ & 3 & - \\
\hline $2 m M$ & $23,35 \pm 1,97$ & 3 & N.S & $9,58 \pm 0,64$ & 7 & $<0,02$ & $17,72 \pm 1,91$ & 6 & $<0,02$ & $8,52 \pm 1,58$ & 3 & N.S \\
\hline $10 \mathrm{mM}$ & $19,04 \pm 2,75$ & 3 & N.S & $6,58 \pm 0,71$ & 3 & $<0.005$ & $15,24 \pm 1,18$ & 3 & $<0.02$ & $7,18 \pm 1,21$ & 3 & N.S \\
\hline $50 \mathrm{mM}$ & $9,51 \pm 1,71$ & 3 & $<0.008$ & $2,51 \pm 0,98$ & 3 & $<0.001$ & $4,15 \pm 0,28$ & 3 & $<0.001$ & $4,56 \pm 0,80$ & 3 & $<0.002$ \\
\hline
\end{tabular}

\begin{tabular}{|c|c|c|c|c|c|c|c|c|c|}
\hline 4-methylvaleric acid & $\mathrm{KIC}$ & $\mathrm{n}$ & $p$ & KMV & $n$ & $p$ & KIV & $\mathrm{n}$ & $p$ \\
\hline- & $16,54 \pm 0,38$ & 2 & - & $15,53 \pm 0,84$ & 3 & - & $20,03 \pm 2,05$ & 3 & - \\
\hline $2 m M$ & $7,88 \pm 1,09$ & 3 & $<0.009$ & $7,73 \pm 0,60$ & 3 & $<0.002$ & $9,80 \pm 0,74$ & 3 & $<0.009$ \\
\hline $10 \mathrm{mM}$ & $1,99 \pm 0,23$ & 3 & $<0.001$ & $3,91 \pm 0,94$ & 3 & $<0.001$ & $5,05 \pm 0,86$ & 3 & $<0.002$ \\
\hline $20 \mathrm{mM}$ & $0,56 \pm 0,32$ & 3 & $<0.001$ & $1,76 \pm 0,87$ & 3 & $<0.001$ & $2,59 \pm 0,63$ & 3 & $<0.001$ \\
\hline
\end{tabular}

\begin{tabular}{ccccc}
\hline DL-methylleucine & KIC & $\mathrm{n}$ & $p$ \\
\hline $\boldsymbol{-}$ & $22,53 \pm 1,92$ & 3 & - \\
$\mathbf{2} \mathbf{~} \boldsymbol{M}$ & $18,96 \pm 2,19$ & 3 & N.S \\
$\mathbf{1 0} \mathbf{~} \boldsymbol{M}$ & $15,11 \pm 1,64$ & 3 & $<0.04$ \\
$\mathbf{2 0} \mathbf{~} \boldsymbol{M}$ & $12,73 \pm 2,53$ & 3 & $<0.04$
\end{tabular}


Table 3. Evaluation of the rate of transamination of different branched-chain 2oxoacids in isolated islets (in vivo transamination rates) at different L-glutamine (Gln) concentrations.

Three groups each of 30 islets were pre-incubated for 1 hour with the Gln concentration indicated. After washing the islets twice with saline, they were further incubated for a second hour in the presence of one of three different branched-chain 2-oxoacids (KIC, KMV and KIV representing oxo-4-methyloxopentanoate, oxo-3methylpentanoate and oxo-3-methylbutyrate, respectively) at $10 \mathrm{mM}$. $\alpha$-Amino acids were measured in islets and incubation medium. The rate of transamination was calculated as the amount of branched-chain $\alpha$-amino acid (Leu, Ileu and Val) released into the incubation medium. $\alpha$-Amino acids were quantified by their emitted fluorescence after being derivatized with o-phftaldialdehyde and separated by reverse phase HPLC. ("n" represents the number of experiments).

\begin{tabular}{|c|c|c|c|c|c|c|}
\hline \multicolumn{7}{|c|}{ Islet amino acid content (pmol / ng DNA) } \\
\hline \multicolumn{7}{|c|}{ OmM L-Glutamine } \\
\hline & Asp & $p$ & Glu & $p$ & GABA & $p$ \\
\hline Go & $0,66 \pm 0,06(8)$ & control & $0,81 \pm 0,07(8)$ & control & $0,73 \pm 0,10(8)$ & control \\
\hline G20 & $0,74 \pm 0,11(6)$ & N.S & $0,57 \pm 0,03(6)$ & $<0.01$ & $0,72 \pm 0,09(8)$ & N.S \\
\hline$K I C$ & $0,57 \pm 0,05(7)$ & N.S & $0,50 \pm 0,04(6)$ & $<0.003$ & $0,39 \pm 0,05(6)$ & $<0.01$ \\
\hline$K M V$ & $1.98 \pm 0,18(6)$ & $<0.0001$ & $2,00 \pm 0,26(6)$ & $<0.0008$ & $0,77 \pm 0,12(6)$ & N.S \\
\hline KIV & $1.97 \pm 0,28(4)$ & $<0.0005$ & $1,10 \pm 0,12$ & $<0.05$ & $0,59 \pm 0,06(5)$ & N.S \\
\hline \multicolumn{7}{|c|}{$0,5 \mathrm{mM}$ L-Glutamine } \\
\hline & Asp & $p$ & Glu & $p$ & GABA & $p$ \\
\hline Go & $1,26 \pm 0,10(8)$ & control & $0,94 \pm 0,07(8)$ & control & $2,17 \pm 0,19(8)$ & control \\
\hline G20 & $1,05 \pm 0,10(6)$ & N.S & $0,85 \pm 0,08(6)$ & N.S & $1,33 \pm 0,14(6)$ & $<0.006$ \\
\hline$K I C$ & $1,64 \pm 0,11(7)$ & N.S & $0,82 \pm 0,12(6)$ & N.S & $0,80 \pm 0,13(7)$ & $<0.0001$ \\
\hline$K M V$ & $3,18 \pm 0,22(6)$ & $<0.0001$ & $2,74 \pm 0,14(6)$ & $<0.0001$ & $1,39 \pm 0,19(6)$ & $<0.014$ \\
\hline$K I V$ & $2,05 \pm 0,19(5)$ & $<0.002$ & $0,99 \pm 0,08(6)$ & N.S & $1,14 \pm 0,11(6)$ & $<0.0005$ \\
\hline \multicolumn{7}{|c|}{$10 \mathrm{mM}$ L-Glutamine } \\
\hline & Asp & $p$ & Glu & $p$ & GABA & $p$ \\
\hline Go & $2,38 \pm 0,22(8)$ & control & $1,24 \pm 0,11(8)$ & control & $3,93 \pm 0,28(8)$ & control \\
\hline G20 & $1,90 \pm 0,13(5)$ & N.S & $1,16 \pm 0,13(5)$ & N.S & $2,32 \pm 0,20(5)$ & $<0.002$ \\
\hline$K I C$ & $1,67 \pm 0,18(7)$ & $<0.003$ & $1,27 \pm 0,20(7)$ & N.S & $1,95 \pm 0,27(6)$ & $<0.0004$ \\
\hline$K M V$ & $4,71 \pm 0,41(6)$ & $<0.0002$ & $3,66 \pm 0,16(6)$ & $<0.0001$ & $2,14 \pm 0,34(6)$ & $<0.0016$ \\
\hline$K I V$ & $4,26 \pm 0,16(5)$ & $<0.0001$ & $1,70 \pm 0,11(5)$ & $<0.02$ & $2,74 \pm 0,26(5)$ & $<0.016$ \\
\hline \multicolumn{7}{|c|}{ In vivo transamination (islet amino acid release) (pmol / ng DNA) } \\
\hline$[G \ln ](m M)$ & Leu & - & Ileu & $p$ & Val & $p$ \\
\hline 0 & $1,92 \pm 0,09(7)$ & control & $1,31 \pm 0,20(6)$ & $<0.014$ & $1,20 \pm 0,13(6)$ & $<0.0007$ \\
\hline 0,5 & $2,56 \pm 0,14(7)$ & control & $2,11 \pm 0,32(6)$ & N.S & $1,70 \pm 0,14(5)$ & $<0.002$ \\
\hline 10 & $3,90 \pm 0,29(7)$ & control & $2,90 \pm 0,55(6)$ & N.S & $2,30 \pm 0,22(6)$ & $<0.001$ \\
\hline
\end{tabular}


Table 4. Effect of $70 \mathrm{mM} \mathrm{KCl}$ depolarization and/or $10 \mathrm{mM}$ oxo-4methyloxopentanoate (KIC) on islet content and release of $\alpha$-amino acids.

Three groups each of 30 islets were pre-incubated for 1 hour with 10 $\mathrm{mM}$ Gln. After washing the islets twice with saline, in order to get free of Gln which would otherwise contaminate HPLC separation) they were further incubated for a second hour with $10 \mathrm{mM}$ oxo-4methyloxopentanoate (KIC). $\alpha$-Amino acids were quantified in islets and incubation medium by their emitted fluorescence after being derivatized with o-phftaldialdehyde and separated by reverse phase HPLC. (" $n$ " represents the number of experiments).

\begin{tabular}{|c|c|c|c|c|}
\hline \multicolumn{5}{|c|}{ Islet amino acid content (pmol / ng DNA) } \\
\hline & GABA & $p$ & Taurine & $p$ \\
\hline control & $4,61 \pm 0,69(7)$ & - & $1,42 \pm 0,24(7)$ & - \\
\hline $10 \mathrm{mM} \mathrm{KIC}$ & $1,85 \pm 0,11(6)$ & $<0.004$ & $1,47 \pm 0,42(8)$ & N.S \\
\hline $70 \mathrm{mM} \mathrm{KCl}$ & $2,25 \pm 0,29(6)$ & $<0.01$ & $0,51 \pm 0,11(7)$ & $<0.005$ \\
\hline $10 \mathrm{mM} \mathrm{KIC+70} \mathrm{mM} \mathrm{KCl}$ & $1.55 \pm 0,14(6)$ & $<0.002$ & $0,74 \pm 0,08(6)$ & $<0.03$ \\
\hline \multicolumn{5}{|c|}{ Islet amino acid release (pmol/ ng DNA) } \\
\hline & GABA & $p$ & Taurine & $p$ \\
\hline control & $0,98 \pm 0,29(8)$ & & $0,31 \pm 0,05(6)$ & control \\
\hline $10 \mathrm{mM} K I \mathrm{C}$ & $1,02 \pm 0,17(6)$ & N.S & $0,31 \pm 0,05(7)$ & N.S \\
\hline $70 \mathrm{mM} \mathrm{KCl}$ & $2,10 \pm 0,37(6)$ & $<0.03$ & $1,00 \pm 0,27(7)$ & $<0.04$ \\
\hline $10 \mathrm{mM} \mathrm{KIC+70} \mathrm{mM} \mathrm{KCl}$ & $2,38 \pm 0,47(6)$ & $<0.02$ & $0,81 \pm 0,16(7)$ & $<0.02$ \\
\hline
\end{tabular}

Table 5. Concentration-dependent suppression of islet 2-oxoglutarete dehydrogenase activity by oxo-4-methylpentanoate (KIC).

Isolated islets were sonicated in a lysis buffer defined in the experimental section. The enzymatic reaction was measured as the amount of NADH produced at saturating concentrations of 2oxoglutarate $(5 \mathrm{mM})$ and $\mathrm{NAD}^{+}(2.5 \mathrm{mM})$. ("n" represents the number of experiments).

\begin{tabular}{cccc}
\hline \multicolumn{4}{c}{$\begin{array}{c}\text { 2-oxoglutarate dehydrogenase activity } \\
\text { (nmol NAD }\end{array}$ / min x mg protein) } \\
\hline KIC & & $\mathbf{n}$ & $\boldsymbol{p}$ \\
\hline $\boldsymbol{-}$ & $7,55 \pm 0,57(6)$ & 6 & control \\
$\mathbf{1} \mathbf{~} \boldsymbol{M}$ & $4,36 \pm 0,58(6)$ & 6 & $<0.003$ \\
$\mathbf{2 , 5} \mathbf{~} \boldsymbol{M}$ & $2,69 \pm 0,44(3)$ & 3 & $<0.0009$ \\
$\mathbf{5} \mathbf{~} \boldsymbol{M}$ & $1,87 \pm 0,61(6)$ & 6 & $<0.00005$ \\
$\mathbf{1 0} \mathbf{~} \boldsymbol{M}$ & $0,48 \pm 0,47(3)$ & 3 & $<0.00009$ \\
\hline
\end{tabular}




\section{FIGURES}

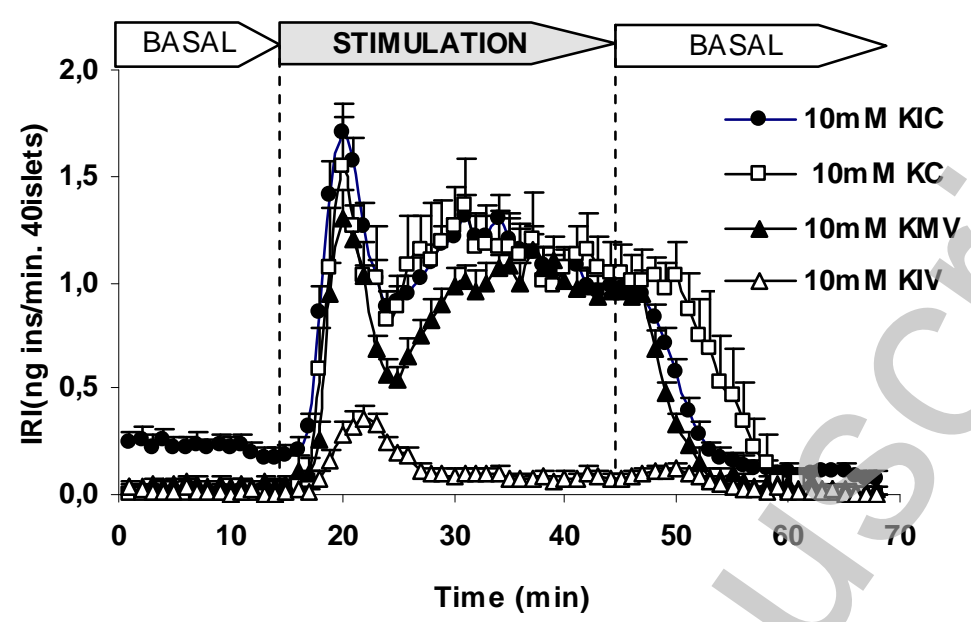

Figure 1

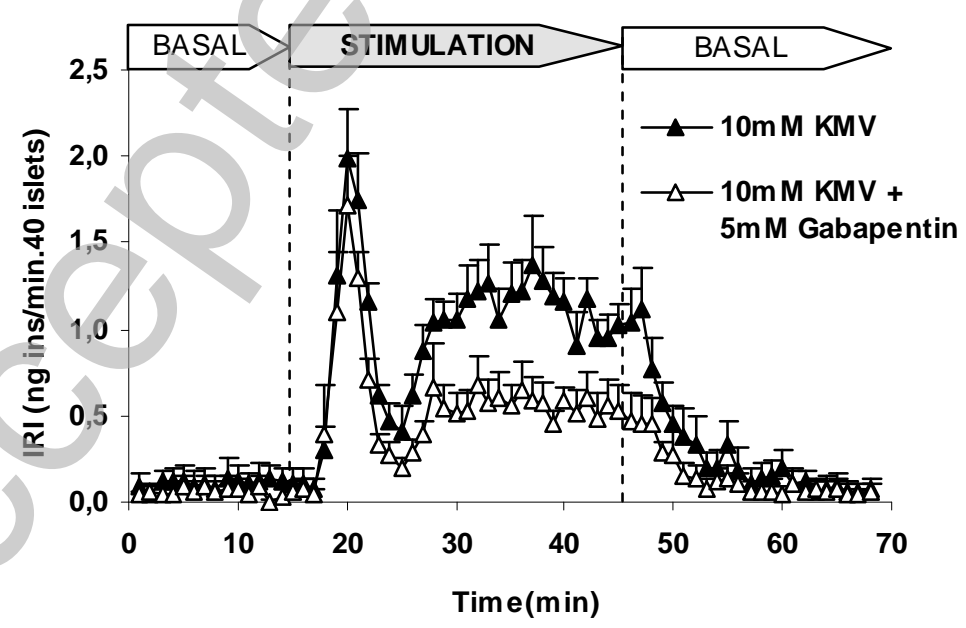

Figure 2 


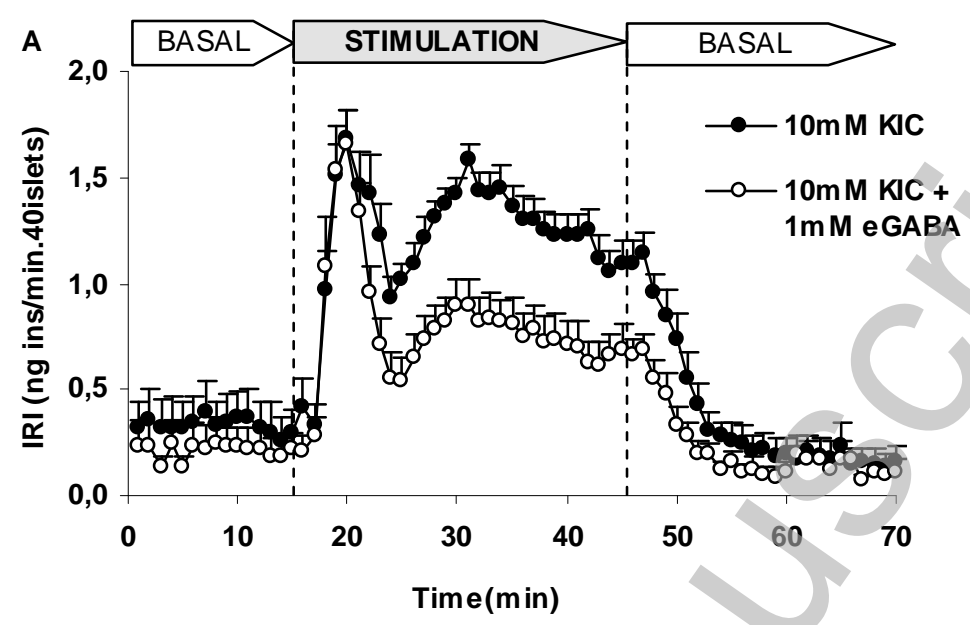

Figure 3A

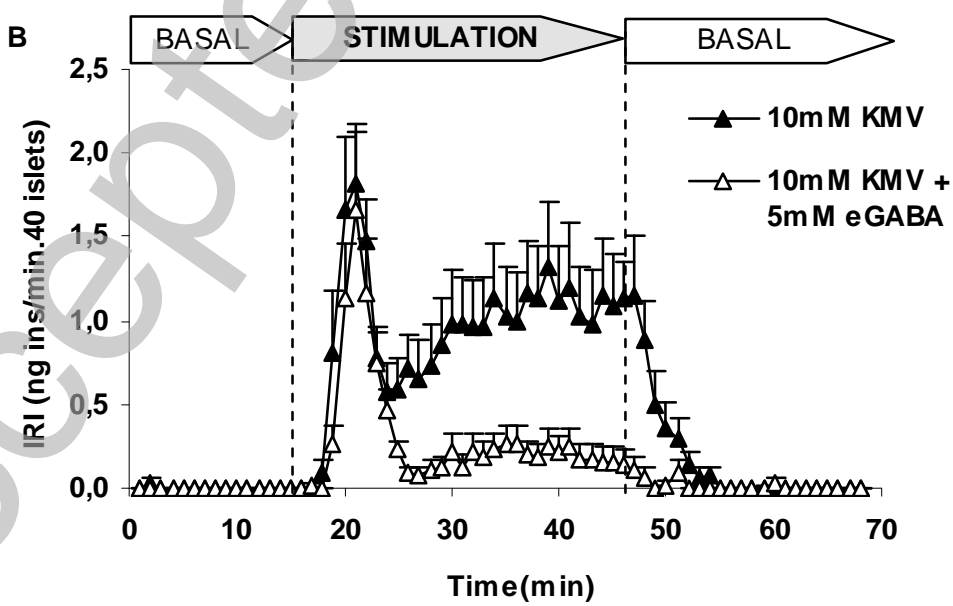

Figure 3B 


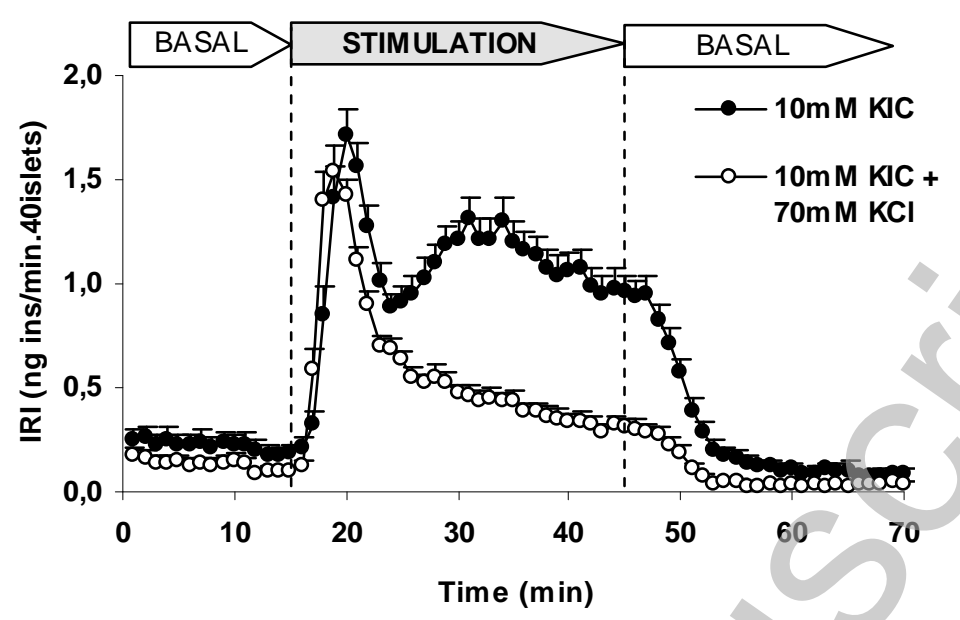

Figure 4

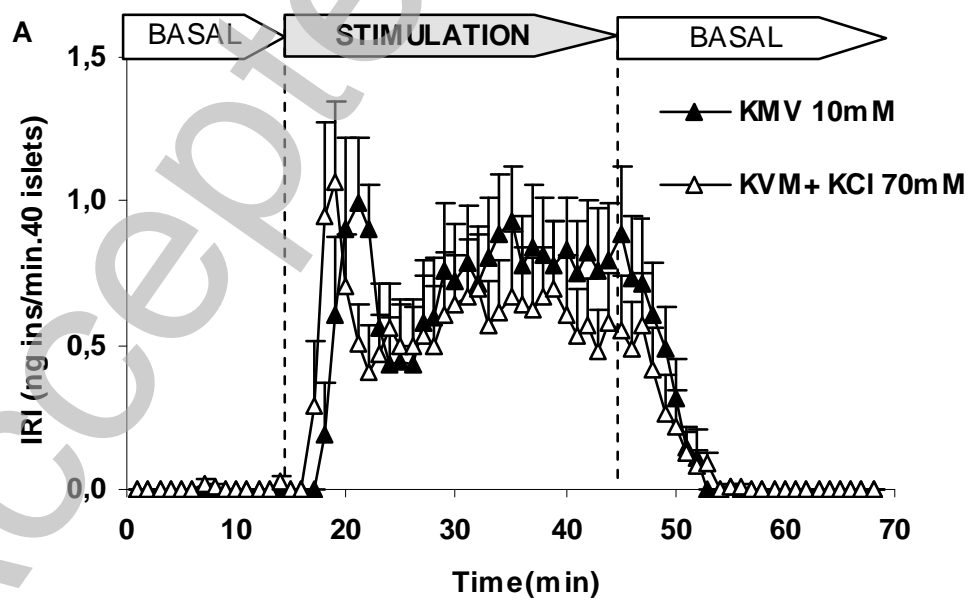

Figure 5A 


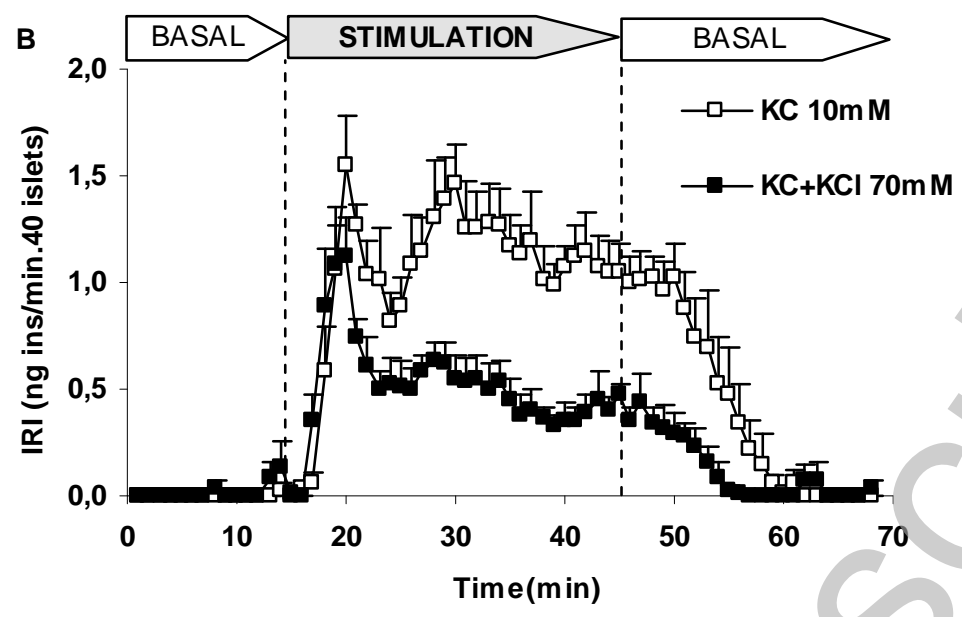

Figure 5B

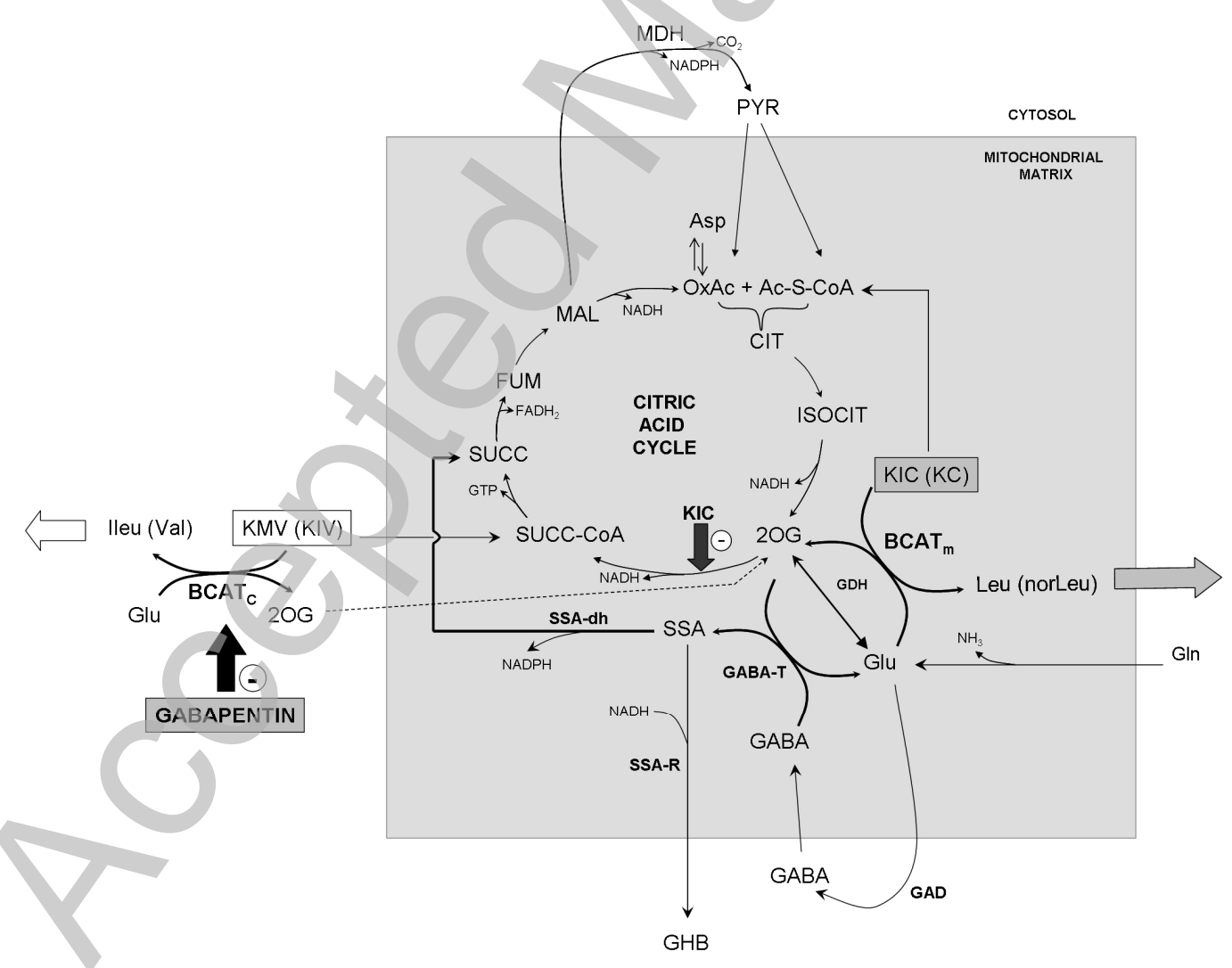

Figure 6 